\title{
Complete Circumferential Osseous Extension in the Acetabular Rim Occurs Regardless of Acetabular Coverage
}

\author{
Keisuke Watarai MD, Fumihiko Kimura MD, Yuho Kadono MD, PhD, \\ Yoon Taek Kim MD, PhD, Mamoru Niitsu MD, PhD, Hiromi Oda MD, PhD, \\ Hirohiko Azuma MD, PhD
}

Received: 8 November 2016/Accepted: 9 May 2017/Published online: 16 May 2017

(C) The Association of Bone and Joint Surgeons (B) 2017

\begin{abstract}
Background Complete circumferential osseous extension in the acetabular rim has been reported to occur in the deep hip with pincer impingement. However, this phenomenon occasionally is observed in dysplastic hips without pincer impingement, and the degree to which this finding might or might not be associated with hip pain, and how often it occurs bilaterally among patients, are not well characterized.

Questions/Purposes (1) To determine the proportion of patients with complete circumferential osseous extension in the acetabular rim using three-dimensional (3-D) CT in patients with and without hip pain who had CT scans obtained for various reasons. (2) To elucidate how often this complete circumferential osseous extension occurred
\end{abstract}

Each author certifies that he, or a member of his or her immediate family, has no funding or commercial associations (eg, consultancies, stock ownership, equity interest, patent/licensing arrangements, etc) that might pose a conflict of interest in connection with the submitted article.

All ICMJE Conflict of Interest Forms for authors and Clinical Orthopaedics and Related Research ${ }^{\circledR}$ editors and board members are on file with the publication and can be viewed on request.

Each author certifies that his or her institution approved or waived approval for the human protocol for this investigation and that all investigations were conducted in conformity with ethical principles of research

K. Watarai, F. Kimura, Y. Kadono, Y. T. Kim, H. Oda (凹),

H. Azuma

Department of Orthopaedic Surgery, Saitama Medical

University, 38 Morohongo, Moroyama-machi, Iruma-gun,

Saitama 350-0495, Japan

e-mail: hoda@saitama-med.ac.jp

M. Niitsu

Department of Radiology, Saitama Medical University, Saitama, Japan bilaterally among those patients. (3) To investigate the relationship between the proportions of patients with complete circumferential osseous extension observed on CT scans among three different acetabular coverage groups: dysplasia, normal, and overcoverage. (4) To determine how often the finding of hip pain was associated with complete circumferential osseous extension.

Patients and Methods Between September 2011 to July 2016, we evaluated 3788 patients with pelvic complaints such as hip, groin, thigh, buttock, or sacroiliac joint pain. We obtained consent from 26\% (992 of 3788) of them, and obtained 3-D CT scans as part of that evaluation. For the current retrospective study, we excluded patients younger than 20 years or 80 years or older (181 patients), patients who had previous hip surgery (185 patients), patients with severe osteoarthritis with Tönnis Grades 2 or 3 (301 patients), and patients who could not have an accurate lateral center-edge (LCE) angle measured owing to poorquality radiographs (24 patients), leaving 301 patients (602 hips) for this analysis. In this study population, patients reported pain in 131 hips (22\%), defined as all types of hip pain except for trauma, including activity pain, pain with sports, pain on motion, and impingement pain; the others did not report hip pain. The mean age of the patients was $56 \pm 16$ years, and the mean LCE angle was $26^{\circ} \pm 8^{\circ}$ (range, $-9^{\circ}$ to $47^{\circ}$ ). We first determined the proportion of patients with complete circumferential osseous extension in the acetabular rim using 3-D CT for those with and without hip pain who had CT obtained for various reasons. We next elucidated how often this complete circumferential osseous extension occurred bilaterally among the patients, and finally we investigated the relationship between the proportion of patients with complete circumferential osseous extension observed on CT scans among the three groups: dysplasia (defined as LCE angles of $22^{\circ}$ 
or smaller), normal, and overcoverage (defined as LCE angles of $34^{\circ}$ or larger) groups. We finally determined how often the finding was associated with hip pain attributable to complete circumferential osseous extension. Results The proportion of patients with complete circumferential osseous extension was 6\% (18 of 301 patients). Eighty-nine percent (16 of 18) of the patients had bilateral complete circumferential osseous extension. There were no differences in the proportions of patients with complete circumferential osseous extension among the three groups: $5.3 \%$ (odds ratio [OR], 1.02 ; 95\% CI, $0.45-$ $2.31 ; \mathrm{p}=0.97$ ), $5.3 \%$, and $7.4 \%$ (OR, 0.70; 95\% CI, 0.28$1.73 ; \mathrm{p}=0.44)$ in the dysplasia, normal, and overcoverage groups, respectively, with the numbers available. Eighteen percent (six of 34) of the hips with complete circumferential osseous extension had pain.

Conclusions Complete circumferential osseous extension in the acetabular rim is relatively uncommon. When it occurs, it usually is bilateral, it occurs regardless of acetabular coverage, and it is associated with pain in a minority of patients.

Level of Evidence Level III, prognostic study.

\section{Introduction}

Osseous extension in the superolateral portion of the acetabulum, also known as roof osteophyte or osseous metaplasia, occasionally is observed in acetabular dysplasia. A possible cause of this is a traction force through the articular capsule or synovial tissue attachment [3]. In diffuse idiopathic skeletal hyperostosis, large paraacetabular osteophytes develop from the articular capsule attachment [14] and also contain intralabral ossifications. Labral ossifications are thought to result from labral damage $[2,10]$. This mechanism of labral ossification was postulated by Seldes et al. [15] in 2001. Labral injury may lead to minor abnormal motion of the femoral head and cause a traction force from the acetabular attachment with subsequent ossification formation in the damaged labrum. However, several theories regarding the nature of labral ossification have been reported. Ninomiya et al. [13] and Byrd et al. [4] suggested it might be the result of enchondral ossification; however, Corten et al. [5] suggested it might result from bone apposition from the acetabular rim. Although labral ossifications are partial (noncircumferential) in most patients, others have osseous extension around the complete circumference of the acetabular rim.

A possible mechanism of complete circumferential osseous extension has been reported to be pincer impingement causing linear contact between the acetabular rim and the head-neck junction [2]. However, complete circumferential osseous extension is observed not only in the deep hip but also in dysplastic hips without pincer impingement. To our knowledge, there have been no published reports regarding the proportion of patients with complete circumferential osseous extension in the acetabular rim, and how often it occurs bilaterally. We also do not know the relationship between the proportions of patients with complete circumferential osseous extension among three different acetabular coverage groups: dysplasia, normal, and overcoverage. In addition, although resection surgery of the painful ossified labrum has been reported $[2,4,13]$, the frequency of pain in patients with complete circumferential osseous extension has not been clarified.

Therefore, we sought (1) to determine the proportion of patients with complete circumferential osseous extension in the acetabular rim using three-dimensional (3-D) CT in patients with and without hip pain who had CT obtained for various reasons; (2) to elucidate how often this complete circumferential osseous extension occurred bilaterally among the patients; (3) to investigate the relationship between the proportions of patients with complete circumferential osseous extension observed on CT scans among three different acetabular coverage groups; and (4) to determine how often the finding of hip pain was associated with complete circumferential osseous extension.

\section{Patients and Methods}

\section{Study Design and Setting}

We retrospectively examined the records of patients seen from September 2011 to July 2016 at Saitama Medical University Hospital in Japan. We evaluated 3788 patients with pelvic conditions such as hip, groin, thigh, buttock, or sacroiliac joint pain. We obtained consent from 26\% (992 of 3788) of them, and obtained 3-D CT scans of the pelvis as part of our evaluation.

\section{Participants and Study Subjects}

Patients 20 to 79 years old with no surgical history and Tönnis Grade 0 or 1 [18] disease of their bilateral hips were included (Fig. 1). Patients were excluded if an accurate lateral center-edge (LCE) angle could not be measured owing to poor-quality radiographs. A total of 301 patients (602 hips) fulfilled the inclusion criteria of this study (Fig. 1). The mean age of the patients was $56 \pm 16$ years (Table 1). One hundred thirty-eight patients were male and 163 were female. Only $22 \%$ (131 of 602) of the hips had 

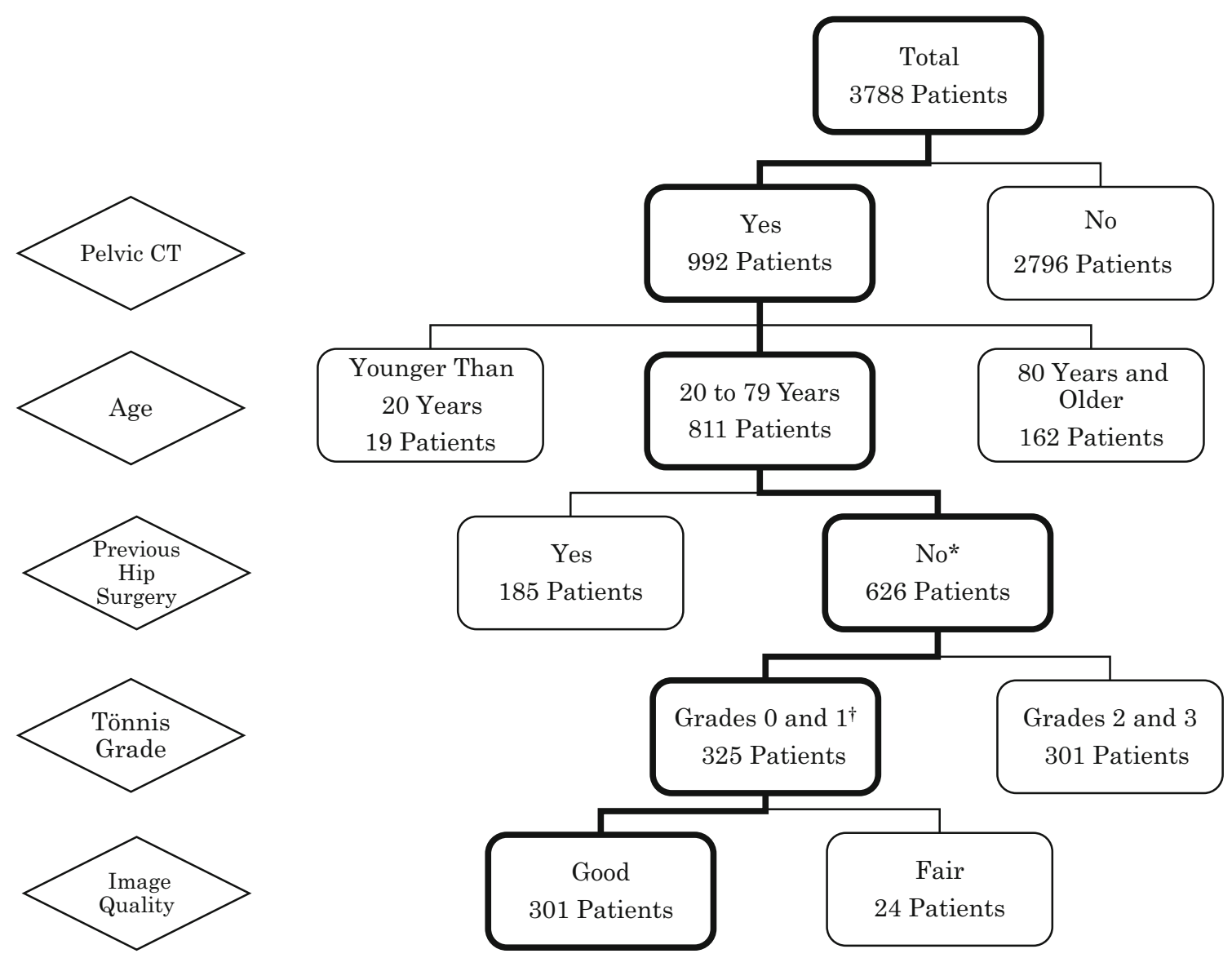

Fig. 1 The inclusion algorithm of this study is shown. *Patients with no surgical history in the bilateral hips; ${ }^{\dagger}$ patients with Tönnis Grades 0 or 1 disease in their bilateral hips.

associated pain judged by the main presentation obtained from review of the patients' medical records, and was defined as all types of hip pain except for trauma, including activity pain, pain with sports, pain on motion, or impingement pain. Hip pain was not reported for the other $78 \%$ of the hips. Ninety-four percent (563 of 602) of the hips had Tönnis Grade 0 disease, and only 39 hips had Grade 1 disease. The mean LCE angle obtained from standardized supine AP pelvis radiographs was $26^{\circ} \pm 8^{\circ}$ (range, $-9^{\circ}$ to $47^{\circ}$ ). Hip and pelvic trauma were the mostprevalent diagnoses for all patients $(34 \% ; 101$ of 301 patients) (Table 2). Lumbar spine disease was the second most-prevalent diagnosis. Patients with ankylosing spondylitis [19] or diffuse idiopathic skeletal hyperostosis [14] were excluded from the study.

\section{Description of Experiment, Treatment, or Surgery}

Complete circumferential osseous extension of the acetabular rim was defined as the ossification shading the entire circumference of the acetabular rim on 3-D CT scans. "Complete" was defined as a hip with osseous extension observed on all slices, and on $360^{\circ}$ scanning in 3D CT. Even if a small gap was seen on $360^{\circ}$ scanning, we defined it as "incomplete". Three-dimensional CT images were obtained using a 16-slice, 64-slice, or 128-slice multidetector CT scanner system (SOMATOM ${ }^{\circledR}$ Emotion 16; SOMATOM ${ }^{\circledR}$ Perspective; and SOMATION ${ }^{\circledR}$ Definition Flesh, respectively; Siemens Healthcare, Forchheim, Germany) using the same protocol. When patients had two or more CT scans during the study period, we assessed the first one.

The LCE angle was measured on pelvic radiographs using OP-A software (FUJIFILM Medical Co, Ltd, Tokyo, Japan). Patients were divided in three groups according to the coverage of the acetabulum: dysplasia, normal, and overcoverage, with LCE angles of $22^{\circ}$ or smaller, $23^{\circ}$ to $33^{\circ}$, and $34^{\circ}$ or larger, respectively [16].

\section{Variables, Outcome Measures, Data Sources, and Bias}

All hips were evaluated independently by two orthopaedic specialists (KW and FK). The patient selection was performed with discussion and agreement of these two 
Table 1. Characteristics of all patients

\begin{tabular}{ll}
\hline Parameter & Value \\
\hline Patients (number) & 301 \\
Hips (number) & 602 \\
Age, mean \pm SD (years) & $56 \pm 16$ \\
Age group (number of patients) & \\
20-29 years & 18 \\
30-39 years & 38 \\
40-49 years & 56 \\
50-59 years & 43 \\
60-69 years & 70 \\
$70-79$ years & 76 \\
Gender (patients: number) & \\
Male & 138 \\
Female & 163 \\
Hip pain (percent positive)* & 22 \\
Tönnis grade (hips: number) & \\
Grade 0 & 563 \\
Grade 1 & 39 \\
Lateral center-edge angle & \\
Mean \pm SD $\left(^{\circ}\right.$ ) & $26 \pm 8$ \\
Range $\left(^{\circ}\right.$ ) & -9 to 47 \\
\hline
\end{tabular}

*Hip pain in patients without trauma.

specialists. The study was approved by the institutional review board of Saitama Medical University Hospital (No. 13-045-3), and was performed in compliance with the Helsinki Declaration. Informed consent was waived because the study is retrospective.

\section{Statistical Analysis and Study Size}

Statistical analyses were performed using Mann-Whitney U or chi-square tests using a bell curve with Excel Statistics Version 2.03 (Social Survey Research Information Co, Ltd, Tokyo, Japan). A p value less than 0.05 was considered statistically significant. The proportions of hips among the dysplasia, normal, and overcoverage groups were compared.

\section{Results}

Complete circumferential osseous extension in the acetabular rim was observed in 6\% (18 of 301 patients) of patients with and without hip pain who had CT scans (Fig. 2; Table 3).

Eighty-nine percent (16 of 18) of the patients had bilateral complete circumferential osseous extension. The
Table 2. Diagnoses of all patients

\begin{tabular}{ll}
\hline Diagnosis or symptom & Patients (number) \\
\hline Hip or pelvic trauma & 101 \\
Lumber spine disease & 64 \\
Osteonecrosis & 47 \\
Acetabular dysplasia & 37 \\
Labrum tear or femoroacetabular impingement & 16 \\
Diffuse idiopathic skeletal hyperostosis & 5 \\
Benign hip tumor & 4 \\
Amyloidosis of the hip & 4 \\
Subchondral insufficiency fracture & 3 \\
Labral ossification & 3 \\
Rheumatoid arthritis & 3 \\
Ectopic ossification of the hip & 3 \\
Transient osteoporosis of the hip & 2 \\
Gout of the hip & 2 \\
Other & 7 \\
\hline
\end{tabular}

other two patients with complete circumferential osseous extension had partial ossification on the contralateral side.

The proportions in the dysplasia, normal, and overcoverage groups were $5.3 \%$ (odds ratio [OR], $1.02 ; 95 \% \mathrm{CI}$, $0.45-2.31 ; \mathrm{p}=0.97$ ), $5.3 \%$ (reference), and $7.4 \%$ (OR, $0.70 ; 95 \%$ CI, 0.28-1.73; $\mathrm{p}=0.44)$, respectively. There were no differences in the proportions among groups, with the numbers available (Table 4). Furthermore, 25\% (four of 16) of the patients with bilateral complete circumferential osseous extension did not have their right and left hips in the same coverage group (Table 5).

Eighteen percent (six of 34) of the hips with complete circumferential osseous extension had pain.

\section{Discussion}

Although most labral ossification is partial in the damaged labrum in the superolateral portion [2,10], we observed a few patients with complete circumferential osseous extension of the acetabular rim. Complete circumferential osseous extension of the acetabular rim has been reported to occur in the deep hip with pincer impingement [2]. However, this phenomenon is observed occasionally in dysplastic hips without pincer impingement (Fig. 2A-B). Various subgroups of labral ossification with differing etiologies may exist. There is little knowledge regarding the number of patients with complete circumferential osseous extension of the acetabular rim, how often it occurs bilaterally, whether there is a relationship between the proportion and acetabular coverage, and whether this finding is associated with hip pain. In our study patients, complete circumferential osseous 

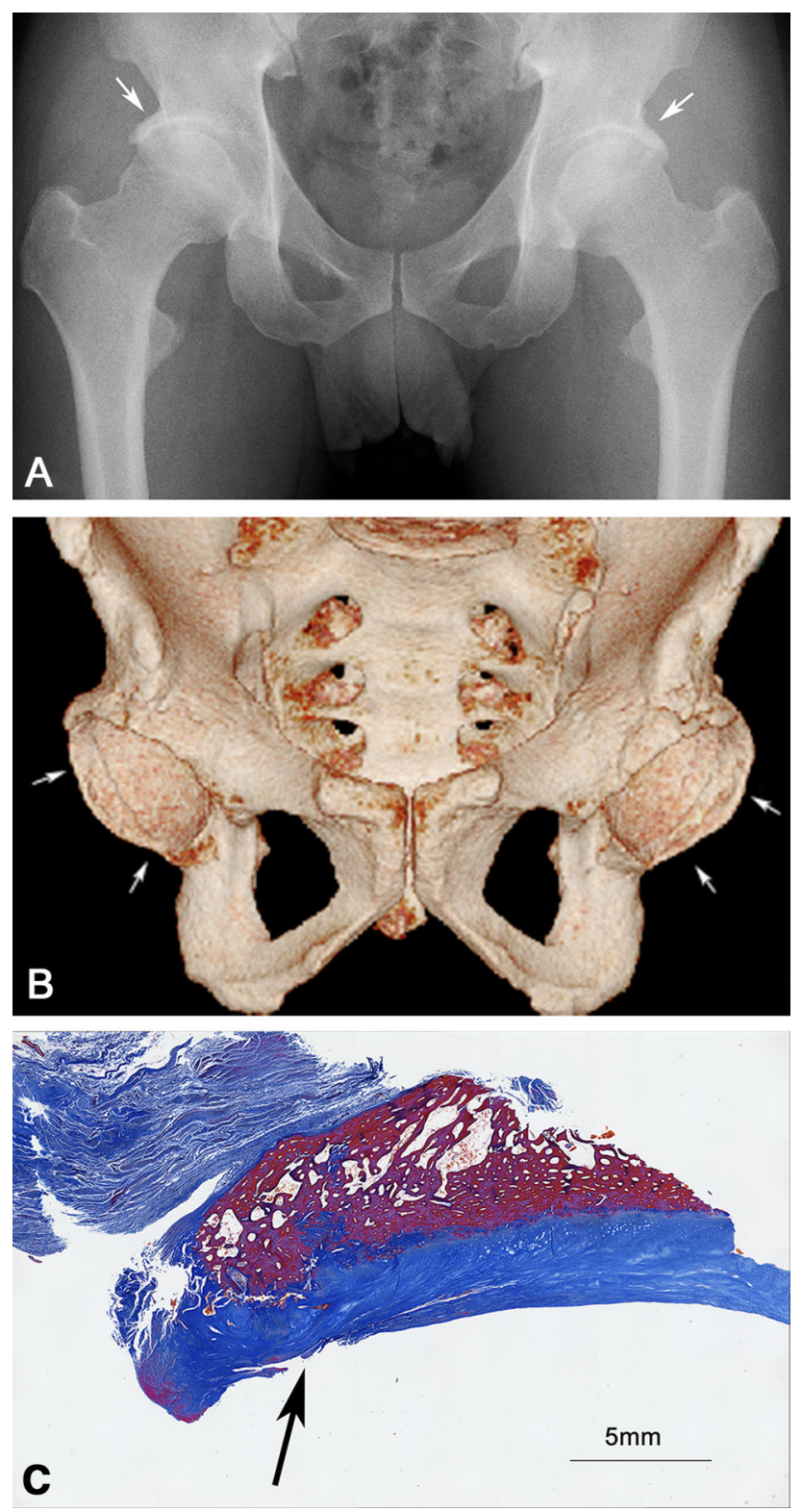

Fig. 2A-C Bilateral labral resection was performed in a 39-year-old man with bilateral hip pain. (A) His AP radiograph showed bilateral osseous extension (arrows) with Tönnis Grade 1 disease. (B) The pelvic 3D-CT scan showed complete circumferential osseous extension (arrows) from the acetabular rim in both hips. (C) Osseous extension existed in the labrum. A trabecular fracture (arrow) was observed around the articular cartilage-labrum transition zone (Stain, Azan; original magnification, $\times 1.25$ ).

extension of the acetabular rim, which is relatively uncommon and usually bilateral, was observed. It is associated with pain only in a minority of patients, and it occurs regardless of the acetabular coverage.

Our study had several limitations. First, this was a retrospective study, and we did not have knowledge of the natural course of the ossification. Second, the patient population in this study was 298 Japanese, one Korean, and
Table 3. Patients with complete circumferential osseous extension in the acetabular rim

\begin{tabular}{|c|c|c|c|}
\hline Variable & Positive & Negative & $\begin{array}{l}\text { p Value (OR; } \\
95 \% \text { CI) }\end{array}$ \\
\hline Patients (number) & 18 & 283 & \\
\hline $\begin{array}{l}\text { Bilateral complete } \\
\text { circumferential osseous } \\
\text { extension }\end{array}$ & 16 & & \\
\hline $\begin{array}{l}\text { Unilateral complete } \\
\text { circumferential osseous } \\
\text { extension }\end{array}$ & 2 & & \\
\hline Proportion of patients (\%) & 6 & 94 & \\
\hline Age, mean \pm SD (years) & $61 \pm 11$ & $55 \pm 16$ & $0.24 *$ \\
\hline Range (years) & $38-76$ & $20-79$ & \\
\hline \multicolumn{4}{|l|}{ Age group (number of patients) } \\
\hline 20-29 years & 0 & 18 & \\
\hline 30-39 years & 2 & 36 & \\
\hline $40-49$ years & 1 & 55 & \\
\hline $50-59$ years & 2 & 41 & \\
\hline $60-69$ years & 10 & 60 & \\
\hline $70-79$ years & 3 & 73 & \\
\hline \multicolumn{4}{|l|}{ Gender (number of patients) } \\
\hline Male & 12 & 126 & $0.07^{\dagger}$ \\
\hline Female & 6 & 157 & \\
\hline Hip pain (positive) $(\%)^{\ddagger}$ & 18 & 22 & $\begin{array}{l}0.30^{\dagger}(0.60 ; \\
0.23-1.59)\end{array}$ \\
\hline \multicolumn{4}{|l|}{ Tönnis grade (number of hips) } \\
\hline Grade 0 & 30 & 533 & $0.20^{\dagger}$ \\
\hline Grade 1 & 4 & 35 & \\
\hline $\begin{array}{l}\text { Lateral center-edge angle } \pm \text { SD } \\
\left({ }^{\circ}\right)\end{array}$ & $28 \pm 7$ & $25 \pm 8$ & $0.23 *$ \\
\hline
\end{tabular}

OR = odds ratio; *Mann-Whitney U test; ${ }^{\dagger}$ chi-square test; ${ }^{\star}$ does not include patients with trauma

Table 4. Prevalence rate of complete circumferential osseous extension according to acetabular coverage

\begin{tabular}{llll}
\hline Parameter & Dysplasia & Normal & Overcoverage \\
\hline Proportion of hips (\%) & 5.3 & 5.3 & 7.4 \\
Complete osseous extension (number of hips) & \\
Positive & 9 & 18 & 7 \\
Negative & 162 & 319 & 87 \\
Odds ratio (95\% CI), p & $1.02(0.45-2.31)$, & 1 & $0.70(0.28-1.73)$, \\
value & 0.97 & & 0.44 \\
\hline
\end{tabular}

two Chinese patients. Although complete circumferential osseous extension occurs regardless of the acetabular coverage, differences between ethnic populations might exist. Third, the mean LCE angle $\left(26^{\circ} \pm 8^{\circ}\right)$ in our study patients is less than the previously reported mean LCE angles in Japanese men $\left(30^{\circ}-35^{\circ}\right)$ and women $\left(28^{\circ}-33^{\circ}\right)$ $[6,9,12,20]$. The reliability of LCE angle measurement is 
Table 5. 16 patients with bilateral hip ossification

\begin{tabular}{llll}
\hline Age (years) & Gender & Right hip & Left hip \\
\hline 38 & M & Dysplasia & Dysplasia \\
38 & M & Normal & Overcoverage \\
49 & M & Normal & Normal \\
50 & F & Dysplasia & Dysplasia \\
56 & M & Overcoverage & Normal \\
60 & M & Dysplasia & Dysplasia \\
61 & M & Dysplasia & Dysplasia \\
61 & F & Overcoverage & Overcoverage \\
65 & M & Overcoverage & Overcoverage \\
65 & F & Overcoverage & Normal \\
66 & M & Normal & Normal \\
67 & M & Normal & Normal \\
68 & M & Normal & Dysplasia \\
68 & F & Normal & Normal \\
73 & F & Normal & Normal \\
74 & F & Normal & Normal \\
\hline
\end{tabular}

another limitation $[8,11,17]$, and subdivision into three groups based on the LCE angle increases this disadvantage. Fourth, although $78 \%$ of hips in this study were asymptomatic, 3-D CT was required for reasons other than pain, indicating that our patients did not represent the general population; therefore, the proportion of patients in the general population may be different. In this study, hip pain was judged based on the main presentation on medical record review. Therefore, there is a possibility that pain was underreported, affecting the frequency of hip pain. Fifth, the same model of multidetector CT scanning systems was not used for all patients; however, this may not have greatly affected the results because the same protocol was used. Finally, the lack of statistical significance in the difference between the three groups may be attributable to the relatively small sample size, and actual differences between these groups cannot be ruled out (Table 4).

In 1980, Azuma et al. [1] reported that osteophytes develop from the articular cartilage-labrum transition zone growing in the labrum and that they appear not only in the weightbearing portion but also throughout the complete circumference of the acetabular rim, especially in elderly patients. To our knowledge, that was the first description of complete circumferential osseous extension in the labrum. The precise pathology of labral ossification remains unclear. Some researchers have reported it as the result of endochondral ossification in the labrum [1,4]. Others [5] postulated that this was not labral ossification, but simply bone apposition superimposed on pincer impingement where the labrum became encased or displaced by new bone formation.
Beck et al. [2] reported five hips with complete circumferential osseous extension and pincer impingement. In our study, complete circumferential osseous extension of the acetabular rim was observed in 6\% (18 of 301) of patients and was relatively uncommon. We also found that $89 \%$ (16 of 18) of patients had bilateral complete circumferential osseous extension. This is the first report, to our knowledge, on the proportion of patients with complete circumferential osseous extension.

Beck et al. [2] also discussed the relationship between pincer impingement and complete circumferential osseous extension and reported that circumferential osseous extension in the labrum was observed in $31 \%$ (five of 16) of hips with pincer impingement. Pincer impingement causes linear contact between the acetabular rim and headneck junction, and thus, ossification of the labrum develops circumferentially $[2,5,7,10]$. However, in our study patients, complete circumferential osseous extension of the acetabular rim was observed not only in the overcoverage group with pincer impingement but also in the dysplastic and normal hip groups. According to the power analysis, with power $=0.8$, alpha $=0.05$, and delta $=0.5$, the number of hips in each group was more than needed $(n=63)$ to identify differences between groups. Moreover, in 25\% (four of 16) of the patients with bilateral complete circumferential osseous extension, the right and left hips belonged to different acetabular coverage groups. This result indicated that complete circumferential osseous extension could develop independently of acetabular coverage and also suggested the existence of unknown factors other than mechanical stress, including pincer impingement or traction.

Ninomiya et al. [13] reported that an extensive resection of the ossified labrum leads to a reduction in pain. In our study, one patient had a trabecular fracture and fracture callus formation (Fig. 2C), which might have been the result of repeated crushing between the ossified labrum and femoral head. This type of fracture might be a reason for hip pain with complete circumferential osseous extension of the acetabular rim. However, ossification did not cause hip pain in all patients. Only $18 \%$ (six of 34) of our study patients experienced pain, which is important for clinicians to know to avoid misjudging the reason for hip pain. Accordingly, the surgical strategy might have to be changed.

In our patient population, complete circumferential osseous extension in the acetabular rim was relatively uncommon, usually bilateral, associated with pain only in a minority of patients, and occurred regardless of the acetabular coverage. It will be important to investigate the natural course and prognosis of complete circumferential osseous extension, such as whether pain appears in 
asymptomatic patients or osteoarthritis progresses, by longterm followup of these patients.

Acknowledgments We thank Hitoshi Taneda MD, PhD (Department of Orthopaedic Surgery, Nishi-Tokyo Central General Hospital) and Kenji Kako MD, PhD (Department of Orthopaedic Surgery, Kako Orthopaedics Clinic) for their helpful suggestions; Michio Watanabe MD and Miyoko Sekikawa MT (both from the Department of Orthopaedic Surgery, Saitama Medical University); and Shinichi Watanabe RT and Tsuyoshi Sasaki RT (both from the Department of Radiology, Saitama Medical University) for excellent technical assistance.

\section{References}

1. Azuma H, Kako K, Itoigawa Y. [Aging process of the acetabulum with special reference to the osteophyte formation][in Japanese]. Nihon Seikeigeka Gakkai Zasshi. 1980;54:153-160.

2. Beck M, Kalhor M, Leunig M, Ganz R. Hip morphology influences the pattern of damage to the acetabular cartilage: femoroacetabular impingement as a cause of early osteoarthritis of the hip. J Bone Joint Surg Br. 2005;87:1012-1018.

3. Bombelli R. Pathogenesis of osteoarthritis of the hip. Osteoarthritis of the Hip: Pathogenesis and Consequent Therapy. Berlin, Germany: Springer-Verlag; 1976:27-47.

4. Byrd JW, Jones KS, Freeman CR. Surgical outcome of pincer femoroacetabular impingement with and without labral ossification. Arthroscopy. 2016;32:1022-1029.

5. Corten K, Ganz R, Chosa E, Leunig M. Bone apposition of the acetabular rim in deep hips: a distinct finding of global pincer impingement. J Bone Joint Surg Am. 2011;93(suppl 2): 10-16.

6. Fujii G, Sakurai M, Funayama K, Hoshi H. [Radiological studies on the hip joint in adult Japanese.][in Japanese]. Orthop Surg. 1994;45:773-780.

7. Ganz R, Parvizi J, Beck M, Leunig M, Nötzli H, Siebenrock KA. Femoroacetabular impingement: a cause for osteoarthritis of the hip. Clin Orthop Relat Res. 2003;417:112-120.
8. Goldman AH, Hoover KB. Source-to-detector distance and beam center do not affect radiographic measurements of acetabular morphology. Skeletal Radiol. 2017;46:477-481.

9. Inoue K, Wicart P, Kawasaki T, Huang J, Ushiyama T, Hukuda S, Courpied J. Prevalence of hip osteoarthritis and acetabular dysplasia in French and Japanese adults. Rheumatology (Oxford). 2000;39:745-748.

10. Ito K, Leunig M, Ganz R. Histopathologic features of the acetabular labrum in femoroacetabular impingement. Clin Orthop Relat Res. 2004;429:262-271.

11. Mast NH, Impellizzeri F, Keller S, Leunig M. Reliability and agreement of measures used in radiographic evaluation of the adult hip. Clin Orthop Relat Res. 2011;469:188-199.

12. Nakamura S, Ninomiya S, Nakamura T. Primary osteoarthritis of the hip joint in Japan. Clin Orthop Relat Res. 1989;241:190-196.

13. Ninomiya S, Shimabukuro A, Tanabe T, Kim YT, Tachibana Y. Ossification of the acetabular labrum. J Orthop Sci. 2000;5:511-514.

14. Resnick D, Shaul SR, Robins JM, Diffuse idiopathic skeletal hyperostosis (DISH): Forestier's disease with extraspinal manifestations. Radiology. 1975;115:513-524.

15. Seldes RM, Tan V, Hunt J, Katz M, Winiarsky R, Fitzgerald RH Jr. Anatomy, histologic features, and vascularity of the adult acetabular labrum. Clin Orthop Relat Res. 2001;382:232-240.

16. Tannast M, Hanke MS, Zheng G, Steppacher SD, Siebenrock KA. What are the radiographic reference values for acetabular underand overcoverage? Clin Orthop Relat Res. 2015;473:1234-1246.

17. Tannast M, Mistry S, Steppacher SD, Reichenbach S, Langlotz F, Siebenrock KA, Zheng G. Radiographic analysis of femoroacetabular impingement with Hip2Norm: reliable and validated. $J$ Orthop Res. 2008;26:1199-1205.

18. Tönnis D, Heinecke A. Acetabular and femoral anteversion: relationship with osteoarthritis of the hip. J Bone Joint Surg Am. 1999;81:1747-1770.

19. van der Linden S, Valkenburg HA, Cats A. Evaluation of diagnostic criteria for ankylosing spondylitis: a proposal for modification of the New York criteria. Arthritis Rheum. 1984;27:361-368.

20. Yoshimura N, Campbell L, Hashimoto T, Kinoshita H, Okayasu Y, Wilman C, Coggon D, Croft P, Cooper C. Acetabular dysplasia and hip osteoarthritis in Britain and Japan. Br J Rheumatol. 1998;37:1193-1197. 